ISSN: $1130-3743$

\title{
LOS CAMINOS DE LA EDUCACIÓN CÍVICO-MORAL. UN DEBATE PERMANENTE
}

\author{
The Roads of Civic-Moral Education. A Permanent \\ Discussion
}

\section{Les routes de l'éducation civique morale. Un débat permanent}

\author{
Andrés SORIANo Díaz \\ Universidad de Granada. Facultad de Ciencias de la Educación. \\ Departamento de Pedagogía. Campus La Cartuja, s/n. 18071 Granada. \\ Correo-e: asoriano@ugr.es
}

Fecha de recepción: enero de 2007

Fecha de aceptación definitiva: abril de 2007

BIBLID [(1130-3743) 19, 2007, 73-97]

\section{RESUMEN}

En el último cuarto de siglo, los estudios y proyectos sobre educación moral han experimentado un notable desarrollo. Tanto en el marco de las experiencias prácticas como en el de la reflexión teórica, los planteamientos se han multiplicado exponencialmente y en distintos países esta preocupación ha adoptado dinámicas y perspectivas diferentes. Con el nombre o la forma que sea, no hay concepción en el campo educativo que no considere la importancia central de la educación moral. En este trabajo, se han seleccionado algunas temáticas, debates y autores que nos parecen representativos de las tendencias actuales en educación moral y hemos planteado una discusión con respecto a dos cuestiones básicas: cuáles deben ser los caminos y los contenidos de la educación cívica y ética, y qué aspectos deben considerarse para formar moralmente a las personas desde una perspectiva integral.

Palabras clave: educación, valores, educación cívica y ética, educación moral. 
SUMMARY

In the last twenty-five years, studies and projects on moral and political education have undergone remarkable development. The principles have been exponentially multiplied in both the framework of practical experiences and in the theoretical field. Also, in different countries this concern has adopted different dynamics and perspectives. Whatever its name and form, there is no conception in the educational field that does not take into consideration the central importance of moral and political education. In this work, some issues, debates and authors, all of them representative of current trends in moral and political education, have been selected and we have raised a discussion with respect to two basic questions: which must be the ways and the contents of civic and ethical education, and which aspects must be considered in order to educate people morally from an integral perspective.

Key words: education, values, civic and ethical education, moral education.

SOMMAIRE

Dans les années 70 du XXè siècle, les études et les projets versant sur l'éducation morale ont connu un notable développement. Soit dans le cadre des expériences pratiques soit dans celui de la réflexion théorique, les approches se sont multipliées exponentiellement et ont adopté différentes perspectives et dynamiques selon les pays. Quelque soit le nom ou la forme acquis, tous les champs pédagogiques considèrent l'éducation morale d'une importance fondamentale. Dans ce travail, quelques thématiques, débats et auteurs nous semblant représentatifs des tendance actuelles ont été sélectionnés et une discussion sur deux questions de base est lancée: en premier lieu, quels devraient être les routes et les contenus de l'éducation civique et éthique et, en second lieu, quels aspects devraient être pris en considération pour former moralement les individus d'après une perspective intégrale.

Mots clés: éducation, valeurs, éducation civique et éthique, éducation morale.

\section{LA EDUCACIÓN Y LOS VALORES}

\subsection{Finalidad de la educación y valor}

Toda educación está fundamentada en valores que merecen realizarse y que toman la modalidad de fin o finalidad de la educación. Nos interesa aquí deshilvanar la madeja para evidenciar el tejido que existe entre el fin y el valor de la educación. Al respecto, Gervilla (1988) señala que la literatura pedagógica ofrece un sentido teleológico de la educación a partir del uso de diferentes términos y matices, tales como fin, fines, meta, propósito, ideal, patrón, objetivo, etc., palabras todas ellas relacionadas entre sí y que se refieren a la finalidad de las acciones 
humanas y de la educación. Son conceptos que dejan claro que la educación siempre tiende hacia un algo, cuya consecución supone un estado más valioso que el que le precede. El valor está relacionado con variados términos que se emplean al referirse a la educación y que, en ocasiones, se confunden por lo que es necesario clarificar sus diferencias.

Podemos distinguir entre valor y bien, recordando que el bien, al menos en la axiología fenomenológica, es el resultado de la realidad más el valor ya que el bien es la realidad valiosa. En cuanto a la diferencia entre valor e ideal, este último se refiere a algo no experimentado, que orienta la acción y no se logra del todo. Los ideales recogen y responden a determinantes culturales y pueden ser considerados como patrones de conducta que presentan un doble carácter de modelo que configura la acción y ofrecen una norma valiosa que la impulsa. El valor guarda una estrecha afinidad con el objetivo, pues no tiene sentido plantearse un objetivo que no sea valioso. En realidad, los objetivos presuponen a los valores implícitamente y se apoyan en éstos aunque no tematicen su propia valiosidad. Las acciones educativas apuntan siempre a finalidades por lo que la taxonomía educativa es útil para precisar el lenguaje de las metas e incluso para darles un cierto orden, pero siempre habrá que elegir entre las posibles finalidades en relación a la concepción que del ser humano se tenga.

Para Fullat (2000) no es posible separar teleología educativa y moral, como tampoco lo es separar al hombre de los valores. Por tanto, la teleología es un saber filosófico que reflexiona sobre la naturaleza, origen y fundamento de los valores que legitiman el proceso educativo actuando como finalidades. El hombre viene provisto de una naturaleza, pero a lo largo de su vida adquiere una segunda que, por decirlo así, le permitirá acabar de hacerse. La determinación de lo correcto de esta última dependerá de lo que previamente se haya elegido como la finalidad de la educación. Desde luego, aquí se hace presente la polémica objetivismo-subjetivismo, cuando nos preguntamos si hay fines y valores objetivos, que no dependan del educador y si el fin o valor de la educación existe naturalmente o es producto de la historia. Fullat introduce una nueva posibilidad que consiste en que quizá el fin de la educación es el resultado de la experiencia educativa organizada por la mente, con lo que habría que admitir ambas opciones: "Sin el fin, como factor epistemológicamente estructurante, las educaciones serían caos para la inteligencia. El fin es, de tal guisa, un a priori, una formalidad epistemológica" (1991, 702).

Pero además de la tesitura epistemológica, debemos tener presente la axiológica. En todo proceso educativo hay implícita una manera de entender al hombre, unas determinadas creencias, por lo que es absurdo hablar de metas concretas de la educación sin reflexionar sobre los proyectos y las utopías implícitas en cualquier fin educativo. Siempre se educa a alguien para algo que va mucho más allá de lo inmediato, se educa para fomentar una determinada concepción de hombre, que se escoge entre varias previamente establecidas.

Otra visión distinta es la de Naval y Altarejos (2000) para quienes la educación es la acción recíproca de ayuda al perfeccionamiento humano, ordenado intencionalmente 
desde la razón, y dirigido desde ella, en tanto que promueve la formación de hábitos éticamente buenos. Al decir esto, podría interpretarse que estos autores consideran los valores como finalidad educativa, sin embargo, ellos cuestionan abiertamente esta pretensión, señalando que la axiología es un extravío teleológico de la educación. Creen que los valores son de naturaleza ideal en el más estricto sentido platónico y piensan que aunque Scheler ofrece una ética más humana y espiritual frente al agobio de la racionalidad formal de Kant, su postura idealista trascendental es criticable al considerar a los valores como esencias ideales que, al mismo tiempo, "son realmente". Tampoco muestran acuerdo con el resto de los autores que han definido el valor como ideal y real. Para ellos, esta discusión no tiene sentido, puesto que es inconveniente enunciar la finalidad de la educación en términos de valores, a riesgo de caer en un utopismo teleológico. Cuando hablan de finalidad se refieren al sentido de la actuación humana y consideran que existen fines naturales y libres, estos últimos dependientes de la voluntad humana. En todo caso, unos y otros pertenecen al orden teleológico pero no siempre axiológico. De acuerdo con su definición, la educación persigue la formación de hábitos, que se distinguen de la costumbre, disposición o inclinación. Se trata de una actuación repetida, inteligente y voluntaria, aunque no plenamente consciente. Concluyen afirmando que la educación puede verse como formación de virtudes y eso es precisamente formar, dar un carácter formativo a la enseñanza.

\subsection{Fines, valores y curriculum}

Una primera dificultad ha sido definir lo que se entiende por finalidad de la educación, una segunda es acordar lo que se entiende por perfeccionamiento humano y, en ese sentido, lo que el currículum debiera integrar para ordenar la actividad educativa en vías a lograr lo deseable.

Existe consenso en que una nota de la educación es el perfeccionamiento humano, pero éste tiene múltiples significados. Dependiendo de los aspectos que se valoren la educación favorece el desarrollo humano, se espera que los educandos sean más valiosos y la calidad de la educación está determinada por la dignidad, profundidad y extensión de los valores que se sea capaz de suscitar y actualizar.

$\mathrm{Al}$ respecto debemos tener en cuenta que no siempre resulta sencillo definir en qué términos debe llevarse a cabo el perfeccionamiento porque aparecerán divergencias cuando se intente delimitar el contenido concreto de tal perfección u optimización, es decir, qué valores, qué sentido y qué orden jerárquico debe fundamentar la educación.

Nos referiremos ahora al currículum y los valores. Partiremos de la idea que engloba objetivos, contenidos, actividades de enseñanza-aprendizaje, evaluación, procesos de interacción personal, organización, etc. Es decir, abarca la totalidad del proceso educativo, si bien acentúa los aspectos de qué enseñar y cómo hacerlo. Cada uno de los momentos del currículum está influido por el valor, pues es ahí 
donde se expresa la concepción de lo que el hombre es y lo que debe llegar a ser, por tanto lo que es la finalidad de la educación.

Ibáñez Martín (1991), por su parte, nos recuerda que básicamente existen tres criterios a utilizar para definir el currículum. El primero es que debe adaptarse a las necesidades de los alumnos, el segundo es la inclusión de contenidos culturalmente significativos y el último es que deben tenerse en cuenta las necesidades de la sociedad. Cualquiera de ellos puede ser completamente arbitrario en la medida que no se fundamente en una referencia inicial y ésta debe ser la dignidad humana.

Gervilla (1991) da cuenta de otros criterios para estructurar el currículum, en función de las teorías axiológicas. Considera que existen tres concepciones del currículum, cada una de las cuales define como objetivo al niño, a la sociedad o a la asignatura. El subjetivismo axiológico conlleva al subjetivismo educativo; desde esta perspectiva, tiene mayor peso educere, sacar lo que ya hay dentro del niño, es la idea de que el objetivo es clarificar los valores, dejando que el niño viva los que ya tiene. En tanto no existen valores universales, la educación deberá ser relativa a las personas y grupos sociales que comparten determinados intereses, no es posible establecer fines y objetivos previos al proceso educativo.

El error del subjetivismo axiológico es identificar valor con interés, puesto que este último es un concepto más estrecho que no puede ser clasificado como un modo idealizado de conducta o un estado final de existencia, ni puede considerarse como patrón, al carecer de obligatoriedad. El currículum basado en el objetivismo es exactamente lo contrario, establece una única forma más allá del tiempo y el espacio. De lo que se trata es de inculcar los valores universales, haciendo válido el principio de educare, es decir, guiar y conducir. Todas las filosofías que conciben al hombre como intemporal se caracterizan por su absolutismo y carácter moralizador, con consecuencias en el ámbito educativo, tales como considerar que es posible enseñar una única verdad a través del aprendizaje de ciertas materias básicas y comunes.

En la línea de quienes han tratado de integrar el carácter objetivo y subjetivo del valor, lo absoluto y lo relativo en una sola perspectiva, nos orientamos por un currículum integral.

Con el calificativo integral", de tan frecuente uso en la actual literatura pedagógica, queremos expresar el currículum que, distanciándose de todo antagonismo, aúna e integra cuantos elementos configuran e interrelacionan la unidad de la persona. Íntegro es aquello que está completo, que no carece de ninguna de sus partes. Considerando como parte de un todo del hombre los antagonismos históricos, el currículo integral es aquel que es, al mismo tiempo, subjetivo y objetivo, que inculca y clarifica valores, que es "educare" y "educere", autoridad y libertad, herencia y medio, naturaleza y cultura; en definitiva, autoeducación y heteroeducación (Gervilla, 1991, 752).

El currículum integral no resuelve la polémica de qué valores y en qué orden jerárquico, puesto que existe una imposibilidad de delimitar científicamente la línea 
que divide la libertad individual y la imposición social. Pero esta propuesta de currículum combina los valores subjetivos y los objetivos, responde a las necesidades del individuo y contempla otros contenidos que se consideran valiosos para la comunidad. De este modelo de educación integral se desprende una concepción de hombre que lo define como animal de inteligencia emocional, singular y libre en sus decisiones, de naturaleza abierta y relacional, en un determinado tiempo y espacio.

\section{LA EDUCACIÓN CÍVICA Y ÉTICA: SU CONTENIDO}

Como hemos podido constatar, aunque con distintos argumentos, los autores reseñados hasta ahora coinciden en otorgar a la educación moral un lugar privilegiado. Ésta puede tomar una multiplicidad de formas en el currículum. Por ejemplo, en España aparece en varios de los ejes transversales de la educación básica, en Argentina toma la forma de asignatura bajo el nombre "Formación Ética y Ciudadana", en el Reino Unido se focaliza en dos asignaturas: "Social Education" y "Citizenship" (Crick, 2000), en México es una nueva asignatura denominada "Formación Cívica y Ética" (Ministerio de Educación, 2000); en Estados Unidos existen diferentes proyectos que han logrado llevar la educación moral, más allá de una asignatura, a la vida toda del aula y la escuela (Reimer, 2001). Además, son numerosas las experiencias en donde se ejecutan programas extraordinarios de formación moral.

Con el nombre o la forma que sea, no hay concepción en el campo educativo que no considere la importancia central de la educación moral, en todo caso las diferencias se localizan en la fundamentación de la misma, en sus prioridades, contenidos y formas. Tanto las distintas concepciones del valor como las diversas teorías éticas repercuten en la discusión sobre lo que debería ser la educación en valores en general, y la educación moral en particular. Es importante señalar, sin embargo, que la relación entre postura filosófica y planteamiento educativo no es lineal ni mecánica. La educación moral es un campo en el que suelen cruzarse distintas disciplinas científicas además de la discusión filosófica. Algunas veces es fácil identificar en una propuesta pedagógica concreta el sustrato filosófico en el que se inspira; en ocasiones, podemos deducir implícitamente la concreción educativa de una determinada manera de concebir la moral, pero con frecuencia la educación moral bebe de distintas fuentes, por lo que es difícil sintetizar de manera ordenada las distintas aportaciones que al respecto se han efectuado.

Antes de hablar de los contenidos de la formación cívica y ética vamos a analizar cada uno de sus términos. Cuando utilizamos la palabra "formación", estamos trascendiendo la mera instrucción pues no se trata de enseñar o transmitir información ni tampoco se busca inculcar o adoctrinar en determinados valores. La formación haría referencia al proceso educativo que busca potenciar las capacidades humanas. En el contexto de la sociedad secularizada, la educación moral ha 
derivado en una moral laica que, en el plano de la relación entre personas y entre éstas y las instituciones, se orienta a partir de ciertos valores que perfilan una serie de relaciones complejas entre educación, ética, sociabilidad y política. A la articulación coherente de estas coordenadas es a lo que llamamos civismo (Camps y Giner, 1998). La formación cívica buscaría fomentar valores, normas y competencias necesarias para la convivencia (en el plano más inmediato de las relaciones sociales) y el ejercicio de la ciudadanía (en el plano de la relación con las instituciones sociales y políticas). El matiz ético de la formación cívica viene dado, sin duda, por la fundamentación filosófico moral de los valores, normas y competencias mencionados. Se trata de formar un ethos individual, como segunda naturaleza, que habilite al agente moral y reconozca la alteridad (González, 2000); más allá aún, se trataría de caminar

\section{[...] hacia la praxis ética, cifrada en la creación de una persona moral, tarea de todos y cada uno en su radical individualidad; y hacia la praxis ético-politica y hacia la genuina paidea, orientadas a la construcción de una real cultura humanística, a tra- vés de acciones e instituciones capaces de propiciar una verdadera educación en los valores humanos, una educación realmente formativa (1997, 147).}

En la demarcación que resulta de trazar unas coordenadas en el mapa inmenso de los valores, definidas en un eje por la integralidad de la educación, y en el otro por el propósito de la ética, destacan, cuando menos, cuatro grandes bloques de contenidos morales que debieran considerarse en el currículum de la educación cívica y ética: los derechos humanos, como expresión universal de valores adquiridos a través de la historia humana; la ciudadanía, como expresión de los valores compartidos en el ámbito de los Estados y comunidades locales, una ética del cuidado de sí y de los otros, como ámbito de la práctica cotidiana de la persona consigo misma y con los que la rodean y, finalmente, una ética de la responsabilidad que se refiere a los riesgos que el desarrollo técnico y su inadecuada utilización suponen para la naturaleza y para la existencia del ser humano.

\subsection{Una ética universal: los derechos bumanos}

Los contenidos de la educación cívica han cambiado a través de los años. Actualmente, cuando se habla de formación cívica y ética se entiende, como señala Cortina (1995), la referencia a valores que los ciudadanos ya comparten. La autora considera que construir una sociedad con vigor ético exige, como elemento indispensable, que aquellos valores en los que esa sociedad cree, es decir, aquellos que cree deberían realizarse, se transmitan a las generaciones más jóvenes a través de la escuela, la familia, el grupo de edad o los medios de comunicación $(1995,17)$.

La educación ética sería la que conduce al hombre desde el carácter con que nace al que va construyendo a lo largo de su vida, apropiándose de una segunda naturaleza humana. Este enfoque pone el centro de la reflexión ética no en la obediencia a 
normas y deberes sino en la adquisición de un carácter que permita el mejor vivir en el marco de una comunidad, pero apelando a principios cuyo carácter universal sería deseable. Se requieren unos mínimos morales compartidos, la potenciación de una ética que permita recomponer el tejido social, buscando no sólo la vía para el establecimiento de leyes y derechos sino el sentido de pertenencia a una comunidad. Estas ideas polemizan con las de distintos autores por su renuncia a considerar el lugar de la razón en el comportamiento moral. Se critica así toda pretensión de pensamiento débil y se apuesta por conocer si en una sociedad pluralista, superada ya la etapa del código moral único, existen unos valores base morales, comunes y fundamentados que sean compartidos por los ciudadanos.

El problema para establecer la base o fundamento de los valores compartidos se encuentra en lo que Weber denominó "politeísmo axiológico" para referirse al resultado de la modernización de los países occidentales: progreso en la racionalización de las estructuras sociales y formas de pensar en detrimento del pensamiento religioso y moral que cohesionaba a la sociedad. Cortina distingue dicho concepto relativista del necesario pluralismo que puede ser comprendido desde una óptica liberal o de la que ella denomina "Socialismo dialógico". La solución al pluralismo moral se resuelve compartiendo unos mínimos morales de justicia aunque se discrepe en unos máximos de felicidad. Sería lo que en otro lugar se ha mencionado como la diferencia entre lo justo y lo bueno.

Según esta visión el contenido de la ética cívica sería aclarar cuáles son los mínimos ya compartidos para tomar conciencia de ellos y potenciarlos. Se cuestiona la elaboración de listas de valores en torno a los cuales educar y aportar su propia propuesta de contenido señalando cuáles son esos mínimos: los derechos humanos de primera, segunda y tercera generación; ciertos valores específicos que se consideran conquistas de la humanidad (libertad, igualdad y solidaridad) y, finalmente, la actitud dialógica.

Desde una perspectiva diferente, Camps (1994) coincide en señalar los derechos humanos como el marco axiológico común

[...] contamos con un conjunto de valores universalmente consensuables, un sistema valorativo que sirve de marco y de criterio para controlar hasta dónde llegan nuestras exigencias éticas individual y colectivamente. Son valores producto de la civilización -no sólo occidental, conviene repetirlo-, producto de más de veinticinco siglos de pensamiento. La democracia griega y el origen de la filosofía, la tradición judeocristiana, la Ilustración, el pensamiento crítico de Marx y Nietzsche, todo ello ha ido dejando un pozo de valores, principios, ideales que se resumen en los llamados derechos fundamentales. Lejos de intentar, una y otra vez, una fundamentación epistemológica -o religiosa- de tales principios, creo que hay que decir, con Bobbio, que la fundamentación de los derechos humanos es la declaración universal de estos derechos realizada en $1948(1994,16)$.

Bárcena, Gil y Jover (1999) consideran central en la educación cívica la cuestión de los derechos humanos y ubican su lugar relevante desde un enfoque que 
pone el acento en la socialización. Para ellos, la autonomía del sujeto radica en la adhesión libre y voluntaria a esos derechos que vienen a ser una especie de código moral construido históricamente:

\begin{abstract}
Educar moralmente será intervenir a través de los procesos de socialización para incrementar los intereses personales y sociales de los individuos que incide tanto en la disminución de desequilibrios entre los valores y las costumbres imperantes y las expectativas que hoy representan y abren los derechos humanos, como en la contribución de la generación de nuevas expectativas que lleguen a ser generalizables $(1999,67)$.
\end{abstract}

Pero es justamente esta definición de los derechos humanos como construcciones históricas, lo que puede suponer un acercamiento relativista a los valores que los sustentan. Son derechos que sólo pueden aspirar a la universalidad si se han de justificar en un plano metafísico, válidos más allá del tiempo y del espacio, asignándoles un carácter metahistórico, independientemente de que su promulgación sea temporal e histórica.

Habermas (1999) no cree que el carácter universal de los derechos humanos se encuentre en lo valiosos que sean los valores que los sustentan, sino en el hecho de que su argumentación, exclusivamente moral, puede formularse desde una racionalidad universal. Aclara que los derechos humanos tienen una especie de estatuto intermedio entre el derecho moral y el positivo, se trata de derechos fundamentales que se dirigen a los ciudadanos en su calidad de seres humanos y no como miembros de un Estado. Pero el concepto de derechos humanos no tiene procedencia moral sino que es el resultado de una acumulación del concepto moderno de derechos subjetivos "lo que le presta la apariencia de derechos morales no es su contenido y con mayor motivo tampoco su estructura, sino su sentido de validez que trasciende los ordenamientos jurídicos de los estados nacionales" (Habermas, 1999, 175).

Como hemos visto, autores de muy variada perspectiva coinciden, en todo caso, en que los valores humanos, por una u otra razón, forman parte de una ética universal, sea ésta producto de una segunda naturaleza humana, del acuerdo convenido socialmente o del resultado de las capacidades universales de razonamiento.

\title{
2.2. Una ética política: la ciudadanía
}

Las personas existen como parte de una comunidad política, por ello, la enseñanza cívica supone la reflexión sobre los derechos humanos, pero no sólo eso. Crick (2000) defiende que paralelamente deben abordarse temas propios de la ciudadanía, cuya realidad precedió incluso a la idea de derechos humanos. Se entiende aquí la ciudadanía como el compromiso y la participación en los asuntos públicos. En todo caso, lo importante es vincular la existencia de derechos con los deberes y responsabilidades. Pero el objetivo de la formación cívica no es sólo 
formar buenas personas sino buenos ciudadanos, por ello debe incluir entre sus propósitos a la educación política, entendida no como adoctrinamiento sino como desarrollo del juicio político. Es decir, la capacidad de comprender, analizar y juzgar los hechos del ámbito político.

Dice Villoro (1997) que todo juicio normativo sobre lo que sea «digno de ser deseado" puede formularse en un juicio valorativo. Luego una ética de la política puede expresarse indistintamente en una ética de valores o normas. Afirma también que los valores y normas a los que refiere una ética política tienen algunas características. En primer lugar tienen validez en un ámbito público, no privado, es decir, se refieren a la representación del orden social, en el que se relacionan los miembros de una unidad política; además no son solamente individuales, también son comunes. Los valores implicados en la política corresponden a relaciones sociales, por lo que son compartidos por las personas involucradas en dichas relaciones, es decir, una ética política trata de los valores que satisfarían el interés general de una unidad política; en tercer lugar están en relación con el poder, desde luego, la frontera entre la sociedad civil y el ámbito del poder es tenue, pero es necesario distinguir las relaciones sociales propiamente políticas de las que no lo son; por último son realizables por lo que las acciones morales políticas tienen que tener realización efectiva en la sociedad y no ser sólo una disposición a realizar el bien común.

Crick (2000) considera que en el ámbito de la formación cívica no es suficiente, aunque sí indispensable, la educación en valores. Para él es fundamental el desarrollo del juicio político. Entiende que la capacidad para formular razones por las cuales se adoptan unas u otras decisiones políticas es fundamental, aunque no siempre implica elegir entre valores. Desde luego, asegura que es muy clara la relación entre la responsabilidad moral y la política, que podría resumirse en el cuidado de los otros, la comprensión, la premeditación y el cuidado cálculo de las consecuencias que nuestras acciones pueden tener sobre los demás.

En el mismo sentido, Bárcena (1997) nos recuerda que el juicio político implica discernir, elegir entre opciones movilizando la capacidad de juzgar políticamente como seres políticos que somos. El autor argumenta que el problema consiste en formar un pensamiento político propio, mostrando así la propia identidad puesto que este tipo de juicio no supone únicamente destrezas intelectuales, sino que al ejercitarlo revelamos las formas en que tenemos construido nuestro carácter, nuestra sensibilidad ética como ciudadanos, nuestros modos de apreciación estética y moral de la realidad política.

Existen dos modalidades de juicio político, el sujeto como espectador y como actor. El primero, observa para comprender el pasado, el segundo recurre al juicio como fundamento de su acción. Se trataría de un juicio que no es monológico, sino que es diálogo anticipado (en el sentido kantiano), que considera los razonamientos de los otros desde una cierta imparcialidad. En cualquier caso el juicio es la actividad política por excelencia: 
Donde el ciudadano muestra o revela su sentido de agencia cívica, en el contexto de la esfera pública, es a través del juicio, cuya naturaleza es la de una facultad esencialmente política. La inhabilidad o incapacidad para pensar representativamente y para el juicio es lo que hace como intentó mostrar (Arendt) en su polémico libro Eichmann en Jerusalén, que el ejercicio del mal sea una banalidad, algo superfluo. Para el ejercicio del mal, como para el del bien, se necesita tener razones, un pensamiento. Otra cosa sería terrible (Bárcena, 1997, 241).

En el terreno concreto de la educación política, Crick (2000) asegura que el desarrollo del juicio político requiere de conocimientos y valores específicos. Se debería buscar aumentar las competencias en la comprensión del lenguaje a través de conceptos básicos, así como la habilidad para relacionarlos con la realidad. Insiste en la importancia de que los estudiantes conozcan, comprendan y utilicen los conceptos, pues sólo por su conducto es posible comprender y explicar relaciones generales y vincular las consecuencias a valores. Pero además de conceptos, es necesario fomentar habilidades y valores. Afirma que el desarrollo de las competencias políticas supone la formación de ciertos valores básicos que denomina "valores procedimentales" y que son libertad, tolerancia, justicia, respeto por la verdad y respeto por la argumentación razonada. Sin éstos, no es siquiera posible pensar en un ejercicio ético de la política.

\subsection{Una ética del cuidado: de los otros y de sí}

Foucault (1999) introdujo la idea de una ética del cuidado de sí que, en especial, en algunos campos de la reflexión moral resulta pertinente. Fue capaz de desvelar las relaciones de poder que permiten establecer símiles entre el ámbito de la política y el de la vida cotidiana. Las relaciones de poder que llegan a convertirse en relaciones de dominio se caracterizan por la posibilidad de las personas de afectar con sus acciones a los miembros de su familia, a sus amigos, a sus alumnos, etc. Frente a ello, las personas tienen que ser capaces de autolimitarse, de frenar sus propios impulsos y deseos de control, mediante prácticas de libertad inscritas en lo que Foucault llama una ética del cuidado de sí. La ética en la política pretendería poner control al ejercicio del poder público, pero una ética del cuidado de sí ampliaría ese esfuerzo al terreno de las relaciones sociales más cercanas, es decir, a todos los ámbitos de nuestra cotidianeidad. Se trata de negarse a ser esclavo de un gobierno, de una persona y de las propias pasiones. La práctica de la libertad sólo adoptará la forma de un ethos deseable si se trabaja sobre uno mismo. O, como dice Kennett (2001), la responsabilidad implica educarse en el autocontrol para convertirse en agencia moral intencional, reconociendo y autoimponiéndose algún tipo de norma que gobierne los proyectos propios, los juicios y las acciones para controlar los deseos que chocan con el bienestar de los otros.

Se trata de una llamada a una ética de la responsabilidad sobre sí mismo y los otros. Reconocemos que la responsabilidad existe antes y después de realizada una 
acción, que es una actitud moral que se deriva de la libertad con la que la persona responde de sus actos voluntariamente. Como señala Guisán (1995), la responsabilidad de la persona moral ha de juzgarse no sólo por la acción sino también por la omisión pues se pregunta ¿qué es más inmoral: robar las joyas de la Corona o dejar que mueran de hambre cientos de niños inocentes? Ella dice que la persona moral debe ir más allá del deber kantiano, para convertirse en un enamorado platónico del bien. Y es en este terreno de la ética del cuidado donde el procedimentalismo se queda corto y aparece la urgente necesidad de formar no sólo a personas capaces de aplicar normas justas sino a seres bondadosos que reclamen la felicidad para sí mismos y para los demás.

Foucault (1999) afirma que el cuidado de sí mismo es ético en sí, pero implica en todo momento a "los otros", para cuidarlos también y para aprender de ellos. Para dar contenido a los ámbitos del cuidado de sí, rememora las tres disciplinas que se ocupan de ello en la Grecia antigua: la dietética, como relación entre el cuidado y el régimen general de la existencia del cuerpo y del alma; la economía, entendida como la relación entre el cuidado de uno mismo y la actividad social y, en tercer lugar, la erótica, como relación entre el cuidado de uno mismo y la relación amorosa. Establece que estos ámbitos corresponden al cuerpo, al entorno y la casa, argumentando, desde esta perspectiva, la relevancia que para la educación cívica y ética tienen los problemas que en el transcurso del desarrollo humano competen al cuerpo, a la familia y al entorno más inmediato.

\subsection{La ética de la responsabilidad}

Para el hombre antiguo y medieval, pretécnico (en la acepción moderna de técnica), la naturaleza era algo duradero y permanente, sometido ciertamente a ciclos y cambios, pero capaz de curar sin dificultad las pequeñas heridas que el hombre le causaba con sus minúsculas intervenciones. Esto ha cambiado radicalmente con la aparición de la ciencia moderna y la técnica que de ella se deriva.

Ahora el hombre constituye de hecho una amenaza para la continuación de la vida en la Tierra. No sólo puede acabar con su existencia, sino que también puede alterar la esencia del hombre y desfigurarla mediante diversas manipulaciones. Todo esto representa una mutación en el campo de la acción humana para la que ninguna ética anterior se encuentra a la altura de los desafíos del presente. Por ello es necesaria una nueva ética: una ética orientada al futuro, que puede ser llamada, con toda propiedad, "ética de la responsabilidad" (Jonas, 1995, 8).

El desarrollo científico y tecnológico ha posibilitado al hombre la adquisición de una situación de poder con respecto a la naturaleza que la ha situado en un lugar donde es susceptible de ser alterada hasta lograr su desequilibrio e incluso su destrucción. Hoy, la diversidad de acciones llevadas a cabo por la técnica ha dado lugar a una serie de objetos muchos de ellos desconocidos e incluso impredecibles en sus consecuencias. Este nuevo poder de la acción humana exige una 
concienciación ética que pueda abarcar este dinámico y cambiante sistema por lo que se imponen cambios y es necesaria una propuesta que contemple a la persona en su relación con la naturaleza.

La naturaleza, en cuanto responsabilidad humana es, sin duda, un novum sobre el cual la teoría ética tiene que reflexionar. Tradicionalmente el alcance de las prescripciones éticas ha estado restringido al ámbito de la relación con el otro en el presente, siendo por tanto de carácter antropocéntrico y dirigidas a la contemporaneidad. Todas ellas comparten tácitamente la idea de que la condición humana permanece, en lo fundamental, fija de una vez para siempre por lo que es posible determinar con claridad y sin dificultades el bien humano y el alcance de sus acciones, de esta manera las actividades humanas quedan claramente limitadas y exentas de responsabilidad (Jonas, 1995).

La capacidad del hombre para alterar o destruir la vida presente o colocar en riesgo la futura hace necesario que el poder de la ciencia vaya acompañado de un nuevo principio, el principio de responsabilidad. Esta ética orientada al futuro de Jonas no se plantea para ser practicada por los hombres venideros, al contrario, debe regir en el presente, es una ética actual que se cuida del futuro y que pretende proteger a nuestros descendientes de las consecuencias de las acciones presentes.

Desde la ética para la responsabilidad se señalan dos tareas básicas, la primera se refiere a la necesidad de maximizar el conocimiento de las consecuencias de nuestras acciones en la medida en que pueden determinar y poner en peligro el futuro destino del hombre, y la segunda plantea, a la luz de este saber, la elaboración de un conocimiento que permita saber qué conviene y qué no es pertinente, qué cosas hay que admitir y cuáles hay que evitar. Este nuevo imperativo ético podría tener formulaciones tales como "obra de tal manera que no pongas en peligro las condiciones de la continuidad indefinida de la humanidad en la Tierra", o bien "obra de tal manera que los efectos de tu acción no sean destructivos para la futura posibilidad de una vida humana auténtica en nuestro planeta".

Siquieira (2001) sostiene que al formular su imperativo de responsabilidad, Jonas está pensando no sólo en el peligro de la destrucción física de la humanidad, sino en su muerte esencial, aquella que adviene de la deconstrucción y la aleatoria reconstrucción tecnológica del hombre y del medio ambiente. Esa nueva ciencia lleva a un conocimiento anónimo, que ya no es hecho para obedecer la verdadera función del saber durante toda la historia de la humanidad, la de ser incorporado a las conciencias en la búsqueda meditada y ponderada de la calidad de vida humana. Hay una interacción entre la investigación y el poder por lo que el nuevo saber es depositado en los bancos de datos y empleado de acuerdo con los medios disponibles y según las decisiones de los que sustentan el poder (Morin, 1993).

El principio de responsabilidad plantea la necesaria preservación de la humanidad y muestra la vulnerabilidad de la naturaleza como consecuencia de la acción del hombre. Nuestra responsabilidad se acrecienta en relación directa a nuestra capacidad de transformación y la conciencia existente sobre los posibles daños causados por nuestras acciones. El mantenimiento de la naturaleza es la condición 
básica de sobrevivencia del hombre, proteger la naturaleza significa preservar al ser humano, por ello no se puede decir que el hombre es sin que se diga que la naturaleza también es, por tanto, el sí a la naturaleza es una obligación del ser humano.

\section{LOS CAMINOS DE LA EDUCACIÓN CÍVICA Y ÉTICA}

En la educación cívica y ética tienen un peso fundamental los valores, pero educar moralmente a la persona o educar a la persona moral es un complejo proceso que involucra distintos aspectos. En la literatura sobre educación moral solemos encontrar planteamientos que aparecen como antagónicos y excluyentes y pareciera ser que o se forma el carácter, los valores, las virtudes, o se desarrolla el juicio moral o los sentimientos morales. Sin embargo existen planteamientos que dan cuenta de la complejidad del fenómeno moral y de la necesidad de vincular los distintos componentes de la realidad personal y social para alcanzar una educación moral que verdaderamente involucre al ser humano de manera integral.

Una de las posturas más interesantes al respecto es la de Berkowitz (1995) quien propone una anatomía moral que incluye los valores, el razonamiento, la emoción, el carácter y la conducta. Para este autor los valores morales son creencias con carga afectiva, relativos a la corrección o equivocación de las cuestiones que son intrínseca y potencialmente perjudiciales y que poseen un carácter universal e inalterable en su prescriptividad. Considera que la educación moral debe incluir tanto la educación en ciertos valores universales como la educación del razonamiento moral, la educación del afecto moral y la educación del carácter y la conducta.

La educación cívica y ética ha sido entendida de muchas maneras en las distintas culturas y en los diferentes periodos históricos. En la segunda mitad del siglo $\mathrm{XX}$, los distintos países han implementado la enseñanza cívica ya sea como fomento del patriotismo, responsabilidad paterna, moral religiosa, centrada en el conocimiento de los deberes y derechos constitucionales, enfatizando el pluralismo y el conflicto de valores, acentuando la educación de los sentimientos, promoviendo la vinculación participativa con la comunidad o desarrollando habilidades específicas para la ciudadanía. En realidad, estas formas de entender la educación cívica no siempre son excluyentes, e incluso podríamos decir que algunos aspectos se refieren a dimensiones distintas que debieran ser consideradas en la formación cívica.

De los muchos aspectos debatidos, nosotros hemos seleccionado tres que, nos parece, deben formar parte de los propósitos de la educación cívica y ética. Aunque en ocasiones se presenten como incompatibles, nosotros, como Berkowitz (1995), creemos que es posible retomar cuestiones de los distintos planteamientos y enriquecer así una educación moral mucho más integral. 


\subsection{Educar el razonamiento moral}

Kohlberg (1992) fue el primero en llevar al terreno de la investigación empírica la búsqueda de relaciones entre el juicio o razonamiento moral y las etapas evolutivas. Los resultados de su indagación le llevaron a formular una propuesta sustentada en la siguiente idea básica: las formas en las que se expresa el razonamiento moral pueden ser catalogadas en seis modelos diferentes que, estando relacionados con la edad, no dependen mecánicamente de ella pudiendo ser considerados niveles de juicio moral. La intervención educativa contribuye a que las personas pasen de una etapa a la siguiente.

- El desarrollo que implica pasar de una a otra etapa no es temporal, sino tan duradero como el desarrollo que operaría sin intervención educativa.

- Esta intervención, para ser efectiva, tiene que asegurar la posibilidad de conflicto cognitivo, conciencia moral, asunción de roles y acceso a una forma de razonamiento que esté por encima de aquella en la que se encuentran los educandos.

- La ayuda adecuada del profesor puede contribuir positivamente a mejorar la capacidad de juicio moral.

Estos hallazgos resultan de suma importancia porque delinean posibilidades y mecanismos para la educación moral. El énfasis no se coloca en la transmisión o promoción de unos determinados valores, por más deseables que puedan ser, sino en la forma de reflexionar y resolver problemas morales. Inculcar los valores de la democracia por la vía de la clarificación de los mismos o mediante programas de modificación conductual no logra un efecto duradero, en cambio, si la intervención educativa se dirige a desarrollar la capacidad estructural de razonamiento moral, se asistirá a cambios realmente estables.

Dos aspectos deben ser considerados: el propósito de la educación del juicio moral no debe ser el acelerar el paso de una etapa a otra, sino evitar el retraso. En segundo lugar, la educación puede y debe procurar que las nuevas capacidades adquiridas se ejecuten en distintos ámbitos de la vida. Con ambos presupuestos, lo que la educación moral buscaría es influir en la profundidad del desarrollo y no en su ritmo.

El sentido de justicia de una persona es lo que es más distintivo y fundamentalmente moral. Uno puede actuar moralmente y cuestionarse todas las normas, se puede actuar moralmente y cuestionarse el bien mayor, pero no se puede actuar moralmente y cuestionarse la necesidad de la justicia (Kohlberg, 1992, 78).

Una de las vertientes que sostiene Kohlberg es la relación entre socialización y desarrollo moral. En este sentido el equipo que integra el Proyecto Minnesota en Estados Unidos (Rest y Narváez, 2001) insiste en que el desarrollo moral es multidimensional y, por tanto, un proceso bio-psico-social, siendo su aspecto más relevante el de la construcción personal de categorías epistemológicas que permiten al 
individuo dar sentido a su experiencia social. Además, incorporan la idea de esquemas morales en vez de etapas, pues consideran que esta concepción es sumamente rígida y da la idea de una escalera por la que se avanza en forma ascendente. Ellos, en cambio, plantean distribuciones movibles en las que el desarrollo sería un cambio en la frecuencia de uso de los razonamientos, moviéndose de lo menos a lo más complejo. Los esquemas, además, son más específicos que las etapas, si bien son más abstractos que lo que en las teorías cognitivas se conoce como esquemas típicos de cognición social.

Dos puntos fundamentales incorpora en su análisis el Proyecto Minnesota, la consideración de los contenidos y el enfoque del aspecto comunitario y cultural de la moral. En el esquema de interés personal, localizan la infancia a la que no asocian características egocéntricas sino que será un momento caracterizado por la vinculación cara a cara. El interés se centra, efectivamente, en uno mismo y en las personas con las que se tiene una relación afectiva. El esquema de mantenimiento de normas es la fase en la que las personas identifican reglas y roles, autoridades de hecho, y se plantean la idea de mantener las normas como forma de cooperación. Básicamente se contempla la percepción de la necesidad de que existan normas en una colectividad, que esas normas se apliquen para todos; que sean claras, uniformes y categóricas; que se comprendan como reciprocidad y que den sentido al establecimiento de estructuras jerárquicas, a la autoridad, etc.

Los investigadores americanos han desarrollado instrumentos que, junto con los dilemas morales, pretenden activar esquemas. Se trata de frases sin concluir que representan líneas de razonamiento que son construidas por los sujetos. Las respuestas son organizadas y clasificadas conforme a los esquemas. Los resultados indican que mientras más consolidada esté una persona en uno de los esquemas, más facilidad y consistencia tiene al procesar la información que se le ofrece en el instrumento, mientras que la mezcla de esquemas se vería reflejada en una menor capacidad de respuesta.

Finalmente, nos parece importante mencionar las aportaciones de Turiel (2002) quien distingue claramente el ámbito moral y el de las convenciones sociales, por lo que asegura que la secuencia evolutiva de los conceptos morales y convencionales debe abordarse de forma diferenciada. Dentro del dominio social se encuentran aquellas cuestiones que el individuo realiza porque le permiten interactuar con las personas, son los aspectos más nítidamente vinculados a la socialización y que él distingue de la actuación moral. Frisancho (2001) distingue tres dominios del conocimiento social: el personal (de las preferencias individuales), las convenciones (el de los comportamientos uniformes, arbitrarios y compartidos) y el moral (donde los comportamientos no son ni arbitrarios ni determinados culturalmente, aunque son factores inherentes a las relaciones sociales). Los estudios realizados por Turiel indican que niños y adolescentes, de manera espontánea, consideran como más graves las faltas que tienen que ver con la ruptura de convenciones que las de reglas morales. Asimismo, tienden a considerar de manera más positiva la realización de actos morales que la adhesión a convenciones sociales. 


\subsection{Educar los sentimientos morales}

Si consideramos a la persona desde una perspectiva integral, sabremos que no basta trabajar en la dimensión cognitiva. Particularmente, cuando se trata de la educación moral se debe tener en cuenta el aspecto afectivo, pues como hemos visto, los valores presentan ambos componentes, el cognitivo y el afectivo. La tendencia actual pues es buscar la manera de integrar ambos aspectos.

Podemos señalar la existencia de dos grandes categorías de emociones morales, las de autocrítica y las prosociales. Las emociones autocríticas resultan de la autoevaluación y autocensura de la persona, mientras que las prosociales son las que implican reacción frente a los otros. Dentro de la teoría de las emociones, se considera que la empatía, la culpa y la vergüenza son emociones morales de orden superior que no surgen sino hasta que se establece en el individuo la conciencia del yo distinta del otro (Zahn-Waxler y Hastings, 2001). De todas ellas, la que más ha sido investigada, y cuyo lugar es relevante en términos educativos, es la empatía y uno de sus corolarios: la compasión.

Existen tres modalidades de empatía: una que es más claramente cognitiva que se refiere a la capacidad de comprender el estado interior de otras personas, y las otras dos más bien afectivas: la capacidad o disposición de vivenciar los sentimientos de los otros y la capacidad o disposición de experimentar compasión por la situación de otros. La empatía en su ángulo cognitivo tiene que ser considerada como un constructo multidimensional que implica la capacidad de captar percepciones, intuir ideas y adivinar emociones de los otros.

Actualmente, las definiciones sobre empatía avanzan en un intento por modelar el componente cognitivo, afectivo y fisiológico, así como en buscar la relación entre esta emoción y el comportamiento. Distintos estudios permiten concluir que los seres humanos están biológicamente predispuestos a reaccionar ante los sentimientos ajenos. Se han podido identificar cuatro etapas en el surgimiento de la emoción: la empatía global, el niño hace suyo el malestar del otro; la empatía egocéntrica, el niño diferencia entre sí y el otro pero aún de manera confusa; la empatía madura, el niño empieza a tratar de responder a las necesidades del otro y, finalmente, la empatía generalizada, el niño está en disposición de responder al dolor ajeno aunque éste se le presente de forma distante.

Se ha encontrado relación entre la capacidad de empatía y la inteligencia, la sensibilidad perceptiva, la extraversión, la franqueza, la autovaloración, los valores altruistas, el juicio moral y las habilidades sociales, entre otras. Por otro lado, se sabe que la empatía también puede estar relacionada con características de la otra persona, tales como ser del mismo sexo, parecerse en algún aspecto, compartir intereses o mostrar valores similares. Finalmente, algunas condiciones de vida asociadas a las personas empáticas son, por ejemplo, el estilo de trato y la propia empatía que los padres, especialmente las madres, muestran hacia sus hijos. Uno de los aspectos más importantes de las investigaciones realizadas es que se confirma una correlación positiva entre empatía y comportamientos prosociales, "cuanto 
mejor puede una persona introyectarse y llegar a sentir la situación apurada de otro individuo, por regla general tanto más pronto estará motivado a un comportamiento prosocial (y tanto menos cometerá actos antisociales)" (Uhl, 1997, 153).

Aunque hay cierto nivel de conocimiento sobre la empatía, se sabe poco respecto a cómo fomentarla. Casi todos los métodos para educar los sentimientos tienen que ver con la reflexión sobre los mismos, partiendo de la idea de que la reflexión de las vivencias afectivas redundará en el surgimiento de determinados sentimientos. En menor medida, se ha experimentado con técnicas como la «imaginación dirigida" o el "juego de roles" que intentan incidir directamente en la afectividad.

Quienes en el campo educativo insisten en reforzar el trabajo sobre los sentimientos morales no deben ser confundidos con los emotivistas en el terreno filosófico. Ortega Ruiz (1999) aclara al respecto que la compasión es un sentimiento mediado por la razón y considera que educar la compasión es clave en la formación moral de la persona. La concibe como ayuda y compromiso con el otro, a la vez que como protesta contra una situación injusta. Se trata de asumir la responsabilidad del cuidado de los otros porque en el mundo sólo hay dos posibilidades: indiferencia o interés por los demás. Sostiene que la compasión equilibra la razón instrumental pues es en realidad solidaridad crítica. Aquí coincide con Alberoni (1995), quien afirma respecto a esta polémica:

La moral es el punto de encuentro del amor desinteresado, sincero, del amor como impulso del altruismo y de la racionalidad. Es la racionalidad que se pone al servicio de este tipo de amor. Ella se vuelve tanto más alta cuanto más intenso, amplio y universal es este amor y cuanto más completa y límpida se vuelve la racionalidad $(1995,35)$.

Argumenta que se trata de ir más allá de la mera comprensión del otro (empatía) para pasar a hacerse responsable de su situación (compasión), lo que nos remite a una ética del cuidado del otro, una ética de la responsabilidad. Concretamente, propone un modelo para fomentar la empatía a partir de tres ejes de acción:

- Entrenamiento afectivo y aprendizaje observacional para reconocer y reaccionar ante el dolor ajeno. Aquí se trataría de un aprendizaje centrado en el entendimiento cognitivo de los sentimientos del otro.

- Experiencias socioafectivas, porque la empatía puede ser aprendida y pensada desde el contexto de la experiencia individual.

- Habilidades sociales y desarrollo moral. Las primeras deben permitir identificar y entender el estado del otro (comportamiento asertivo, habilidades comunicativas, autocontrol, etc.).

Finalmente, el autor defiende la idea de que la educación moral debe avanzar e influir en experiencias que modifiquen el comportamiento de las personas, y no sólo sus ideas sobre el bien y la justicia, lo cual es más factible si los sentimientos de la persona se involucran y no sólo su razón. 
Guisán (1995) aboga por el lugar de los sentimientos morales y sintetiza su propuesta en los siguientes puntos: los sentimientos morales juegan un papel predominante, en la llamada etapa convencional puede y debe ejercerse intervención educativa, los adultos pueden y deben incidir en el desarrollo moral, los contenidos morales son relevantes y, finalmente, es pertinente considerar las consecuencias de nuestros actos para un adecuado desarrollo del razonamiento moral. Añade a los puntos anteriores otros principios relacionados, en cierto modo, con una perspectiva de género: la educación debe fomentar la sensibilidad por igual en niños y niñas para lograr un adecuado desarrollo moral, la educación debe concienciar respecto a que el bienestar propio y ajeno son a la vez un derecho y un deber debiéndose educar en la benevolencia. Finalmente, cree que es tarea educativa la potenciación de las pasiones racionales, la ampliación de los sentimientos de sympatheia, la sensibilización frente a problemáticas sociales e individuales y la comprensión de que la búsqueda de la felicidad constituye el máximo derecho y deber de la persona moral.

\subsection{Educar el carácter moral}

En Estados Unidos, la educación del carácter es hoy la vía más utilizada para la educación moral. Aparece ante lo que algunos autores consideran una crisis de valores como resultado de las carencias formativas de la familia, la iglesia, la escuela, la televisión y el grupo de pares. Ha sido fuertemente criticada por conservadora y manipuladora, sin embargo, consideramos que esta modalidad introduce aspectos que deberían ser considerados a fin de acceder a un planteamiento integral. En la educación del carácter hay dos conceptos con los que nos topamos permanentemente y cuyo significado debe ser aclarado, la virtud y el hábito. Las virtudes son rasgos del carácter que frenan las pasiones, son excelencias del carácter que producen actos propios (Medina, 2001). Respecto al hábito, Uhl (1997) lo define como una propiedad de la personalidad, disposición psíquica relativamente duradera para un cierto tipo de comportamiento. No es natural ni se origina mediante procesos naturales de maduración sino que se aprende mediante el esfuerzo de habituación, por lo que su aprendizaje supone la repetición múltiple de un modo de vida o comportamiento. Así, entre los teóricos de la educación del carácter, encontraremos referencias permanentes o bien a los hábitos o bien a las virtudes, cuando no a ambos. Wynne $(2000,87)$ nos recuerda que el vocablo carácter procede de la raíz griega que significa "marcar": "El carácter involucra la socialización de la gente de manera que su conducta visible -su comportamiento, ya sea en actos o en palabras- refleje la formación de virtudes internas tales como la amabilidad, el valor o la diligencia".

Para Peters (1984), la educación moral es a la vez implantación de principios morales y transmisión de hábitos virtuosos, proceso que debe iniciarse en edades tempranas. De hecho, en su concepción sobre la educación misma, considera dos 
vertientes: el adiestramiento intelectual para formar el entendimiento, y el fomento de hábitos para formar la voluntad. Para Medina (2001), la educación moral estaría focalizada precisamente en el entrenamiento de la voluntad

La finalidad de la educación moral es, para Peters, la formación de un carácter autónomo que siga los dictados de una recta razón no oscurecida por un desviado uso de la propia libertad. El educando, por tanto, está en disposición de conocer lo que está mal o bien a través de su razón e ir asumiendo e interiorizando la corrección de su primera intuición [...] Los hábitos, para Peters, se refieren a las acciones del individuo, a una tendencia o facilidad para actuar en sentido correcto. Es decir, se pretende una acción automática del individuo en sus acciones buenas, una inclinación, una actuación moral casi sin esfuerzo, lograda a través del entrenamiento diario durante años en el ejercicio de las virtudes $(2001,131)$.

McLean (1992) en defensa de la educación del carácter, asegura que ni la mejor tabla de valores y virtudes permite a la persona responder a las pruebas del día a día. Distingue entre atributos y actos, y afirma que el trabajo de la conciencia moral no comprende sólo el juicio teórico sino el desarrollo y ejercicio de la self possesion, por lo que la tarea de la educación moral es formar una personalidad que convierta los valores tradicionales en hábitos que determinen la acción espontánea de las personas. Pero como afirma Uhl (1997), una de las críticas más consistentes a la educación del carácter es aquella que duda de hasta qué punto el hábito impide el juicio moral. Desde luego, hay una discusión filosófica implícita también cuando se asegura que el acto es moral aunque no haya sido racionalmente decidido. Asegura que la evidencia empírica demuestra que los actos del ámbito moral en ningún caso llegan a ser totalmente inconscientes, pues aunque se produzcan de manera en apariencia automática, siempre hay un trasfondo de decisión consciente.

Debemos hacer notar que para los teóricos de la educación del carácter el papel de la comunidad es clave. Centran su atención en la relación entre lo individual y lo colectivo porque el hombre, en tanto ser social, construye su moralidad como miembro de un grupo social. La persona se encuentra inmersa en una comunidad con la que comparte un origen, una historia, ciertas tradiciones y valores que son los que le permiten formar su identidad personal. Es decir, el individuo no podría ser tal sin la comunidad de la cual forma parte. Por tanto, el papel de la educación debe ser estimular la adhesión a los valores comunitarios. Desde luego, los autores de esta teoría reconocen que puede observarse un cierto relativismo axiológico, pero salen al encuentro con algunas consideraciones que debieran ser tenidas en cuenta a la hora de seleccionar los valores colectivos de una comunidad: que puedan ser confrontados con un estándar externo, que admitan la posibilidad de regenerar valores en el marco comunitario y que respeten las creencias y valores de otras comunidades. Para estos autores no hay posibilidad de desacuerdo en el contexto comunitario porque los valores y los fines son simplemente reconocidos y aceptados y no son resultado de procesos racionales: la tarea de la educación moral tiene que ver con la formación de corazones decentes, generosos, 
virtuosos y justos más que con enseñar a pensar de acuerdo con ciertos parámetros lógicos.

Ryan y Lickona (1992) proponen lo que denominan un enfoque comprensivo de la educación del carácter, con el fin de enseñar valores morales tanto directa e indirectamente desarrollando el tipo de carácter capaz de poner en práctica dichos valores. Parten de tres premisas:

- El Bien se define en función de valores morales universales que afirman la dignidad humana.

- Dos valores universales son el núcleo de la moralidad pública que debe ser enseñada: la responsabilidad y el respeto.

- El respeto es el lado restrictivo de la moralidad que impide afectar lo valioso. Incluye el respeto por sí mismo, por los demás y por el medio ambiente. Otros valores como la honestidad, civilidad y equidad son formas de respeto.

- La responsabilidad es el lado activo de la moralidad. Incluye responsabilizarse de sí mismo y de las propias acciones y trabajar para mejorar las condiciones humanas. Valores como la cooperación, el compromiso y la valentía son formas de responsabilidad.

- Para educar el carácter es necesario trabajar con el conocimiento, el sentimiento y la acción moral.

A partir de estas ideas, sistematizan nueve estrategias que deben seguirse en la escuela para educar el carácter: el profesor debe ser un modelo y mentor moral para los estudiantes, la escuela fungirá como una comunidad moral, la disciplina moral tiene que ser especificada, se fomentará un ambiente democrático en el salón de clase, los valores tendrán que estar integrados en los planes y programas de la escuela, se fomentará el aprendizaje cooperativo, se procurará el desarrollo de una conciencia sobre el trabajo, se estimulará la reflexión moral y se enseñará a resolver conflictos. Insisten que parte de las estrategias educativas radican en ir más allá del aula y de la escuela misma, logrando integrar a los padres de familia y a la comunidad en los proyectos educativos.

Wynne (2000) también señala los pasos de la formación del carácter: identificar rasgos y conductas virtuosas, atribuir prestigio a las personas que ostentan esas virtudes, procurar que los educandos practiquen similares virtudes, criticar a las personas que muestran comportamientos diferentes. De esta forma, el estudiante podría identificar la virtud y a quien la posee, así como a aquellos que carecen de actos y pensamientos virtuosos. Uhl (1997) argumenta que se corrobora una correlación positiva entre la repetición persistente de una acción y la formación del hábito y sostiene los efectos visibles de los programas que enfatizan la actuación moral: se aprenden técnicas adecuadas de actuar conforme a reglas, se adquiere seguridad y confianza en la propia capacidad, se comprende la legitimidad de las 
normas morales, se aprenden los deberes morales como autoimpuestos y se obtiene satisfacción, autorrespeto y orgullo.

Como se puede ver, en cuanto a métodos educativos, estas ideas no se distinguen mucho de lo que también se conoce como educación de las actitudes. Alcántara (1998), por ejemplo, propone métodos para educar las actitudes: la motivación, la imitación, la actuación, la autoevaluación, el compromiso, la autoinstrucción y la programación ambiental. Salmerón (2000) disiente de los teóricos de la educación del carácter en muchos sentidos, pero considera que debieran retomarse algunas aportaciones que realizan en vistas a construir una salida integradora. En primer lugar, recupera la noción aristotélica del hombre como ser social, pues permite comprender mejor el proceso de aprendizaje que no sólo opera en el terreno de las operaciones cognitivas, sino mediado por las influencias sociales, tal y como fue planteado por Vigotsky. No basta el proceso de maduración personal ni la actividad experimental individual, sino que el aprendizaje implica la asimilación y comprensión del bagaje cultural. Para ella, no es necesario optar por la enseñanza de ciertos valores compartidos o por el juicio crítico, pues ambos son posibles y necesarios.

En segundo lugar, le parece que cada vez es más aceptado que el aspecto cognitivo forma parte del desarrollo moral pero no es lo único. En ese sentido, el hábito y la experiencia práctica, tal y como las concibió Aristóteles, no se contravienen con la reflexión y el juicio. Incluso menciona aportaciones de la psicología psicoanalítica que respaldan desarrollar, cultivar y educar los rasgos del carácter a partir de la práctica. Y no porque la práctica sustituya a la reflexión o a la inteligencia crítica, sino porque les permite apoyarse sobre la estructura psíquica general de la personalidad (Salmerón, 2000).

Por último, no queremos dejar de mencionar el planteamiento de Puka (2001), quien desde una posición crítica de la educación del carácter, retoma algunos planteamientos de lo que se ha denominado "alfabetización moral" para distinguirlo de la inculcación y el adoctrinamiento, del que ha sido severamente acusada la teoría en cuestión. El autor narra un interesante proyecto de educación moral denominado "Sea su propio héroe" que, a partir de algunas cuestiones semejantes a los modelos de ejemplaridad, introduce variantes que buscan fomentar la reflexión y la adhesión voluntaria a ciertos valores. Es decir, como Salmerón y Berkowitz, Puka ve posible retomar aspectos de la educación del carácter en un esfuerzo por lograr una formación integral de la persona.

A modo de conclusión, hemos querido defender una propuesta de educación ética desde una perspectiva integral. Creemos en la necesidad de construir planteamientos que integren de forma un tanto ecléctica distintas opciones; como señalan diversos autores, en el terreno de la educación moral lo mejor que podemos hacer es poner a dialogar las filosofías, teorías científicas y experiencias. Por ello, nos parece pertinente terminar este trabajo con la siguiente cita de un grupo de investigadores holandeses: 
LOS CAMINOS DE LA EDUCACIÓN CÍVICO-MORAL. UN DEBATE PERMANENTE

\begin{abstract}
Los filósofos y educadores morales sustentan una concepción cada vez más pluralista de cómo debe entenderse la conciencia moral en la niñez y también en la edad adulta [...] Se desmantelaron las antiguas divisiones entre el juicio, el sentimiento y la acción morales a fin de representar más adecuadamente la moral como un conjunto de tendencias prosociales posibles de generar acciones. Cabe denominar dichas tendencias como "sensibilidades morales", pues contribuyen fundamentalmente a lo que los individuos se inclinen a pensar y a actuar desde una perspectiva moral. Por lo demás, se las puede interpretar como formas de la inteligencia (juicios morales) o como formas de la sensibilidad afectiva (sentimientos morales). En ambos casos, el conjunto de inclinaciones arraigadas que llamamos "sensibilidades morales" corresponde a lo que Aristóteles denominó "perspicacia" y que constituye la base del propio carácter moral (Van Haaften, Wren y Tellings, 9-10).
\end{abstract}

\title{
BibliografíA
}

AlBeroni, F. (1995) Valores. 23 reflexiones sobre los valores más importantes en la vida. Barcelona, Gedisa.

AlCÁnTARA, J. A. (1998) Cómo educar las actitudes. Barcelona, CEAC.

BÁrCENA, F. (1997) El oficio de la ciudadanía. Introducción a la educación política. Barcelona, Paidós.

Bárcena, F.; GIL, F. y Jover, G. (1999) La escuela de la ciudadanía. Educación ética y politica. Barcelona, Paidós.

BerKowitz, M. (1997) El desarrollo moral individual como consecuencia de la educación democrática, en KohlBerg, L.; POwer, F. C. y Higgins, A. (eds.). La educación moral. Barcelona, Gedisa, 293-325.

BERKOWITZ, M. W. (1995) Educar a la persona moral en su totalidad, Revista Iberoamericana de Educación, 8.

CAMPS, V. (1994) Los valores de la educación. Madrid, Anaya.

CAMPS, V. y Giner, S. (1998) Manual de civismo. Barcelona, Ariel.

CARR, D. (1991) Educating the virtues. An essay on the philosophical psychology of moral development and education, citado en SALMERÓN, A. M. (2000). La berencia de Aristóteles y Kant en la educación moral. Bilbao, Desclée de Brower.

Cortina, A. (1995) La ética de la sociedad civil. Madrid, Alauda Anaya.

CRICK, B. (2000) Essays on citizenship. London, Continuum.

De SiquerRa, J. E. (1998) Ética e tecnociencia: uma abordagem segundo o principio da responsabilidade de Hans Jonas. Londrina, UEL.

- (2001) El principio de responsabilidad de Hans Jonas, Acta bioeth., 7 (2), 277 285.

Foucault, M. (1999) Estética, ética y bermenéutica. Obras esenciales, vol. III. Barcelona, Paidós.

Frisancho, H. S. (2001) Aportes de la psicología a la comprensión del fenómeno moral. Ponencia presentada en la Cátedra Andina de Educación en Valores, en http://www. campus-oei.org/valores/frisancho.htm.

Fuldat, O. (2000) Filosofía de la educación. Madrid, Síntesis.

(c) Ediciones Universidad de Salamanca

Teor. educ. 19, 2007, pp. 73-97 
GeRVILLA, E. (1991) Fundamentos filosóficos del currículo: valores y currículo, en VV.AA. Filosofía de la educación boy. Madrid, Dykinson.

- (1998) Los derechos humanos en el proceso de mundialización, en Ortega, J. A.; DelGADO, M. L. y CaRRASCOSA, M. J. (coords.). Derechos bumanos, educación y comunicación. Granada, Centro UNESCO de Andalucía.

GonzÁlez, J. (2000) El poder de eros. Fundamentos y valores de ética y bioética. México, Paidós-UNAM.

GUISÁN, E. (1995) Introducción a la ética. Madrid, Cátedra.

Habermas, J. (1999) La inclusión del otro. Estudios de teoría política. Barcelona, Paidós.

IbÁÑ̃ez MarTín, J. A. (1991) Política del currículo y dignidad humana, en VV.AA. Filosofía de la educación hoy. Madrid, Dykinson.

JONAS, H. (1995) El principio de responsabilidad. Ensayo de una ética para la civilización tecnológica. Barcelona, Herder.

KenNeTr, J. (2001) Agency and responsibility. A common-sense moral psychology. Oxford, Oxford University Press.

Kohlberg, L. (1992) Psicología del desarrollo moral. Bilbao, Desclée de Brower.

MCLEAN, G. F. (1992) The person, moral growth and character development, en Mclean, G. F. y Ellrod, F. E. Philosophical foundations for moral education and character development: act and agent. EUA, The Council for Research in Values and Philosophy.

MEDINA, C. J. (2001) Sistemas contemporáneos de educación moral. Barcelona, Ariel.

Ministerio de EduCACIÓn DE MÉxICO (2000) Formación Cívica y Ética. Guía de estudio para profesores en servicio de escuelas secundarias generales, técnicas y telesecundarias. México, SEP.

Morin, E. (1993) El método: la naturaleza de la naturaleza. Madrid, Cátedra.

Naval, C. y Altarejos, F. (2000) Filosofía de la Educación. Pamplona, Eunsa.

ORTEGA RutZ, P. (1999) The role of compassion in moral education, Journal of moral education, 28 (1), 5-17.

PeTERS, R. S. (1984) Desarrollo moral y educación moral. México, FCE.

PuKA, B. (2001) La educación del carácter y el niño de corta edad, en VAN HAAFTEN, W.; WREN, T. y Teldings, A. (comps.). Sensibilidades morales y educación, vol. 1. Barcelona, Gedisa.

Reimer, J. (1997) De la discusión moral al gobierno democrático, en Kohlberg, L.; Power, F. C. y Higgins, A. La educación moral. Barcelona, Gedisa.

- (1997) El enfoque de la comunidad justa: la democracia de un modo comunitario, en KOHLBerg, L.; POWer, F. C. y Higgins, A. La educación moral según Lawrence Koblberg. Barcelona, Gedisa.

REST, J. R.; NARVÁEZ, D. et al. (2001) A neo-Kohlbergian approach to morality research, Journal of Moral Education, 29 (4), 381-395.

RYan, K. y Lickona, T. (1992) Character development: the challenge and the model, en RYAN, K. y LICKONA, T. Character development in schools and beyond. EUA, The Council for Research in Values and Philosophy.

SAlmerón, A. M. (2000) La herencia de Aristóteles y Kant en la educación moral. Bilbao, Desclée de Brower.

Turies, E. (2002) El mundo social en la mente infantil. Madrid, Alianza Editorial.

UHL, S. (1997) Los medios de educación moral y su eficacia. Barcelona, Herder. 
Van HaAften, W.; Wren, T. y Tellings, A. (comps.). Sensibilidades morales y educación, vol. 1. Barcelona, Gedisa.

VILLoro, L. (1997) El poder y el valor. Fundamentos de una ética política. México, Fondo de Cultura Económica.

Wynne, E. A. (2000) La educación moral en las escuelas. México, documento fotocopiado.

ZAHN-WAXLER, C. y HaStings, P. D. (2001) El desarrollo de la empatía: pautas adaptativas e inadaptativas, en Van HaAften, W.; Wren, T. y Teluings, A. (comps.). Sensibilidades morales y educación, vol. 1. Barcelona, Gedisa. 